\title{
How Cognitive Control, Autistic and Schizotypal Traits Shape Context Adaptation of Divergent Thinking
}

\begin{abstract}
Divergent thinking, the ability to generate multiple ideas from different perspectives, is considered a central component of the creative thinking process. While context, personality traits, and cognitive control abilities have individually been shown to have large effects on divergent thinking, their interrelationship is yet to be elucidated. In 83 healthy participants (Males $=42 \%$ ), we investigated how context adaptation of divergent thinking is related to normal variations in autistic and positive schizotypal traits as well as to proactive and reactive cognitive control strategies. Context adaptation of divergent thinking-defined as the variance in the proportion of unique to total responses of a drawing divergent thinking task performed across four different contexts - was predicted by a 3-way interaction of autistic traits, positive schizotypal traits, and cognitive control. Specifically, increasing reactive control improved context adaptation when positive schizotypal traits were high and autistic traits were low, while increasing proactive control was associated with improved context adaptation when both autistic and positive schizotypal traits were high. Both modes of cognitive control can enhance the ability to generate unique ideas across contexts, but this depends on the individuals' specific combinations of autistic and positive schizotypal trait levels.
\end{abstract}

Keywords: autistic traits, context adaptation, creativity, proactive control, reactive control, schizotypy.

\section{INTRODUCTION}

Divergent thinking is typically defined as the ability to generate multiple ideas from different perspectives (Cropley, 2006; Guilford, 1950; Lubart, Mouchiroud, Tordjman, \& Zenasni, 2015), and while it does not represent creativity per se, it is often perceived as an estimate of the potential for creative problem solving (Runco \& Acar, 2012). Along with convergent thinking - the ability to integrate and evaluate existing information and knowledge to arrive at optimal solutions (Guilford, 1950) — it is used in psychological theories to characterize the creative process (Cropley, 2006; Finke et al., 1992) and is even considered by some as the essential capacity of the creative process (Robinson, 2011). In this context, divergent thinking has been viewed both as (a) a malleable ability that is susceptible to context and situational influences (Cropley, 2006; Intasao \& Hao, 2018; Runco, 2004; Runco \& Pritzker, 1999), and (b) an "endowed trait" underpinned by a specific personality trait profile (Claridge \& McDonald, 2009; Mohr \& Claridge, 2015) and cognitive control abilities (Benedek, Jauk, Sommer, Arendasy, \& Neubauer, 2014; Carlsson et al., 2000; Ellamil, Dobson, Beeman, \& Christoff, 2012; Kowatari et al., 2009). While context, personality traits, and cognitive control abilities have individually been shown to have large effects on divergent thinking (Ma, 2009; Runco, 2004), their interrelation is yet to be elucidated. This study investigates how personality traits and cognitive control determine context adaptation of divergent thinking.

Context adaptation of divergent thinking can be defined as the ability to adjust flexibly to conditions or environments in developing new ideas or products (Cohen, 2012). Research suggests that performance on divergent thinking or creativity tasks that rely on divergent thinking can be hindered or facilitated,

[Correction added on Jan 11, 2021 after first online publication: the word 'convergent' in the title has been updated to 'Divergent'.] 
depending on the ability of the individual to adapt to a given context or situation (Cropley, 2006; Maddux \& Galinsky, 2009; Runco \& Pritzker, 1999). Notably, Cropley (2006) has highlighted that while shifting contexts and crossing boundaries are important processes of divergent thinking, considering the particular situation can minimize the production of absurd associations (e.g., replacing steel reinforcing rods with spaghetti due to their similarities). Moreover, Dai et al. (2012) have shown that variation in school, home, and neighborhood environments can impact the development of divergent thinking abilities of adolescents. Since the generation of ideas can be affected when the individual is required to shift from one context to the next, context adaptation of divergent thinking can thus be seen as an indicator of the individual's potential to manifest divergent thinking abilities in novel contexts. If divergent thinking is an estimate of the potential for creative problem solving (Runco \& Acar, 2012), context adaptation of divergent thinking might thus be a useful index of one's creative potential across contexts and situations.

Both divergent thinking and context adaptation have been linked to cognitive control—operationalized as an attentional mechanism involved in the control of information processing (Braver, Paxton, Locke, \& Barch, 2009; Groborz \& Necka, 2003). With respect to context adaptation, Braver et al. (2009) suggested that context adaptation could be linked to reactive and proactive modes of cognitive control. According to this Dual Mechanisms of Control, proactive control is associated with a tendency to anticipate and maintain a context representation in memory to process relevant information, while reactive control is associated with a tendency to process contextual information instantly without relying on previously constructed contextual cues. It is worth noting that the Dual Mechanisms of Control model has parallels with the dual process model that has been discussed in the field of creativity, which proposes that creativity may involve both automatic/flexible and controlled/persistence processes (respectively, reactive and proactive control in terms of the Dual Mechanisms of Control model) (Beaty, Benedek, Silvia, \& Schacter, 2016; Nijstad, Dreu, Rietzschel, \& Baas, 2010; Sowden et al., 2015; Zhang et al., 2020). Since these modes of cognitive control can be flexibly engaged, they can variably influence how information is processed and used, particularly when adapting to the demands of complex tasks or contexts (Braver et al., 2009; Braver, 2012; Gonthier, Macnamara, Chow, Conway, \& Braver, 2016, Mäki-Marttunen et al., 2019, Marklund \& Persson, 2012). For example, Mäki-Marttunen et al. (2019) showed that reactive and proactive control strategies were adaptively deployed during the AX-Continuous Performance Task that required individuals to update context under different conditions of memory demands.

Furthermore, studies revealed a prominent role for cognitive control in divergent thinking (Benedek et al., 2014; Groborz \& Necka, 2003; Zabelina \& Ganis, 2018; Zabelina \& Robinson, 2010). For example, divergent thinking was associated with higher attentional flexibility between frequent global and rare local attentional levels and vice versa (Zabelina \& Ganis, 2018). Moreover, the propensity to perceive meaningful coincidences has been associated with reduced memory capacity (Rominger et al., 2019), which has been linked to reliance on reactive control (Gonthier, Zira, Colé, \& Blaye, 2019). Therefore, we suggest that cognitive control may be key in one's ability to successfully adapt divergent thinking across different contexts. Specifically, we reason that context adaptation of divergent thinking can be facilitated by calling upon proactive control (by facilitating context processing in advance through sustained and anticipatory maintenance of goal-relevant information), or reactive control (by providing a "fresh" way of looking at context in a stimulus-driven fashion).

The role of personality traits in the creative process, including divergent thinking, has been confirmed in numerous studies $(\mathrm{Ma}, 2009)$ and has largely been investigated in terms of creative personality scales and the five-factor model of personality (Feist, 2010). A parallel line of research stems from the association of underlying cognitive styles with certain psychopathologies, such as autism and schizophrenia, and their expression at nonclinical, personality-variation levels with enhanced creative abilities (Acar, Chen, \& Cayirdag, 2018; Fitzgerald \& Lyons, 2013). We focus on autistic and positive schizotypal traits-subthreshold features of autism and schizophrenia within the neurotypical population-because they have been proposed to play prominent roles in both divergent thinking (Abu-Akel et al., 2020; Claridge \& McDonald, 2009; Crespi, Leach, Dinsdale, Mokkonen, \& Hurd, 2016; Jung, 2014) and cognitive control-related processes (Abu-Akel, Apperly, Spaniol, Geng, \& Mevorach, 2018; Spaniol, Shalev, \& Mevorach, 2018), and because they can co-occur in the same individual (Abu-Akel, Wood, Hansen, \& Apperly, 2015; Sampson et al., 2020; Sierro, Rossier, \& Mohr, 2016).

With respect to divergent thinking, positive schizotypal traits have been fairly reliably linked to enhanced performance on divergent thinking tests. This has been reported by numerous studies showing that individuals with high positive schizotypy, biased for remote associative processing (Mohr \& Claridge, 2015), show significant advantages (both in terms of fluency and originality) on both verbal and figural divergent thinking tasks (Abu-Akel et al., 2020; LeBoutillier, Barry, \& Westley, 2014; Rominger et al., 2017; O'Reilly, Dunbar, \& Bentall, 2001; Wang et al., 2017). In contrast, research, although limited, reported both positive and 
negative association of autistic traits with divergent thinking. For example, higher autistic traits have been shown to have negative association with divergent thinking (in terms of fluency) (Best, Arora, Porter, \& Doherty, 2015; Jankowska, Omelańczuk, Czerwonka, \& Karwowski, 2019), but with higher number of unique responses (Best et al., 2015). Indeed, higher autistic traits might be associated with impaired semantic processing that underlies fluency in the right hemisphere, but with intact left hemisphere, and thus unimpaired top-down executive processing underlying production of unusual responses (Best et al., 2015).

With respect to cognitive control, research suggests that individuals with elevated positive schizotypal traits or at-risk state for psychosis are associated with deficits in applying proactive control and appear to have no major deficit in, and even a bias toward reactive control (Abu-Akel et al., 2018; Niendam et al., 2014). In the context of creative thinking research, it has been shown that the association of positive schizotypy with increased ability of unusual associations - defined as statistically infrequent or "unique" associations - was not related to proactive interferences, that is, when irrelevant and older information had to be deleted from memory (Rominger, Weiss, Fink, Schulter, \& Papousek, 2011, 2019). Rominger et al. (2017) also reported that the positive association between positive schizotypy and divergent thinking might coincide with reduced top-down cognitive control, measured in terms of reduced inhibitory control of auditory information. In contrast, autistic traits appear to be associated with enhanced performance on tasks requiring proactive control and worse performance in tasks requiring reactive control (Abu-Akel et al., 2018; Spaniol et al., 2018). For example, Spaniol et al. (2018) have linked the deployment of proactive control to performance benefits observed in individual with high autistic traits on tasks that required shifting from local to global contexts as well as from social to nonsocial contexts. We are not aware of studies that investigated the role of cognitive control with respect to the association of autistic traits with divergent thinking. Our study seems novel in this respect. Taken together, it is intriguing to observe that autistic and positive schizotypal traits might be associated with contrasting effects both in terms of their association with divergent thinking and their modes of cognitive control (proactive vs. reactive). Accordingly, it is conceivable that both autistic and positive schizotypal traits may interactively moderate the putative relationship between cognitive control and context adaptation of divergent thinking.

The current study had two aims: (a) to investigate the association between cognitive control and context adaptation of divergent thinking and (b) the modulatory role of autistic and positive schizotypal traits of this association. To do so, we developed a drawing task, adapted from the figural part of the Torrance Test of Creative Thinking (Torrance, 1974), which assesses divergent thinking across contexts. In our task, participants received a basic shape (e.g., a circle) and were asked to draw objects, using this shape, in four different contexts (see method for details). For cognitive control, we used the Proactive Behavioural Index (PBI) of the AX Continuous Performance Task (AX-CPT), where positive scores represent proactive control and negative scores represent reactive control (Braver, Barch, \& Cohen, 1999; Braver et al., 2009).

We surmised above that both proactive control (by facilitating context processing in advance) and reactive control (by providing a "fresh" way of looking at context) could facilitate the generation of unique ideas across contexts. Accordingly, we predicted that PBI scores of the AX-CPT task would be associated with context adaptation of divergent thinking. We further hypothesized that this association would likely be moderated by the relative levels of autistic and positive schizotypal traits within the individual, given evidence suggesting that these traits might be associated with contrasting cognitive control strategies and effects on divergent thinking. Specifically, if autistic and positive schizotypal traits were, respectively, associated with proactive and reactive control strategy preferences (Abu-Akel et al., 2018; Niendam et al., 2014; Spaniol et al., 2018), it might be conceivable to predict better context adaptation with increasing autistic traits and greater proactive tendencies, as well as better context adaptation with increasing positive schizotypal traits and greater reactive tendencies.

\section{METHOD \\ PARTICIPANTS}

The sample consisted of 83 neurotypical adults (mean age $=22.37$; $\mathrm{SD}=2.93 ; 48$ females). The overall sample size was estimated using an a priori power analysis ( $\mathrm{G}^{*}$ Power, Version 3.1.9.2; Faul, Erdfelder, Lang, $\&$ Buchner, 2007), with an alpha $=0.05$, power $=0.80$, and a minimum medium effect size $\left(f^{2} \geq 0.15\right)$, for a full factorial regression analysis with three predictors: Autistic traits, positive schizotypal traits and cognitive control (PBI). Students were recruited from three Swiss universities: a polytechnic university $(N=26)$, an art and design university $(N=24)$, and from the school of social sciences of a general university $(N=33)$, directly on campus or via an e-mail announcement (for sample characteristics and details see results section, Table 1). Following Abu-Akel et al. (2020), collecting data from these different universities 
were intended in order to minimize skewed distributions often reported for personality questionnaires when administered in circumscribed populations (e.g., in psychology students (Hurst, Nelson-Gray, Mitchell, \& Kwapil, 2007) or science students (Baron-Cohen, Wheelwright, Skinner, Martin, \& Clubley, 2001)). Participants self-reported no history of psychiatric illness, epilepsy, neurological disorders, brain injury or alcohol or substance abuse problems.

\section{AUTISM SPECTRUM QUOTIENT (AQ)}

The AQ is a self-report questionnaire used to assess autistic personality traits within the general population (Baron-Cohen et al., 2001). The AQ consists of 50 items with responses given on 4-point Likert scale from "Definitely Agree" to "Definitely Disagree." Each item is scored as 0 or 1, with total scores ranging from 0 to 50. The AQ consists of five subscales (of 10 items each) representing the 5 dimensions characterizing the Autism Spectrum Disorder (ASD): social skills; attention switching (increased focus of attention); attention to details; communication; imagination. For the purposes of this study, we only used the AQ total score. The AQ's internal consistency in our study was adequate $(\alpha=0.71)$ and comparable to previously reported values (Baron-Cohen et al., 2001; Sierro et al., 2016). In the Supplementary Information, we

TABLE 1. Characteristics of Overall Sample and Subgroups

\begin{tabular}{|c|c|c|c|c|c|c|}
\hline \multirow[b]{2}{*}{ Variable $^{a}$} & \multirow[b]{2}{*}{ All $(N=83)$} & \multicolumn{3}{|c|}{ University } & \multicolumn{2}{|c|}{ Stats } \\
\hline & & $\begin{array}{c}\text { Social Sciences } \\
\text { (SS) }\end{array}$ & $\begin{array}{l}\text { Science and } \\
\text { Tech (ST) }\end{array}$ & $\begin{array}{c}\text { Arts and } \\
\text { Design (AD) }\end{array}$ & $\chi^{2} / \mathrm{H}$ & $p$-value ${ }^{b}$ \\
\hline Gender (F/M) & $48 / 35$ & $20 / 13$ & $10 / 16$ & $18 / 6$ & 7.01 & .030 \\
\hline Age & $22.37 \pm 2.93$ & $\begin{array}{l}22.91 \pm 3.00 \\
(48.86)\end{array}$ & $\begin{array}{l}21.54 \pm 2.63 \\
(34.63)\end{array}$ & $\begin{array}{r}22.54 \pm 3.05 \\
(43.29)\end{array}$ & 3.90 & .142 \\
\hline Year of Education & $17.45 \pm 1.80$ & $\begin{array}{l}17.70 \pm 1.55 \\
(46.17)\end{array}$ & $\begin{array}{l}16.85 \pm 1.80 \\
(34.35)\end{array}$ & $\begin{array}{l}17.75 \pm 2.03 \\
(44.56)\end{array}$ & 4.08 & .130 \\
\hline IQ (fNART) & $110.54 \pm 5.25$ & $\begin{array}{l}111.56 \pm 5.40 \\
(46.52)\end{array}$ & $\begin{array}{l}110.68 \pm 4.80 \\
(41.96)\end{array}$ & $\begin{array}{l}108.99 \pm 5.36 \\
(35.83)\end{array}$ & 2.75 & .253 \\
\hline AQ Total & $18.04 \pm 5.68$ & $\begin{array}{l}16.52 \pm 5.72 \\
(34.42)\end{array}$ & $\begin{array}{l}19.50 \pm 4.67 \\
(50.15)\end{array}$ & $\begin{array}{l}18.54 \pm 6.30 \\
(43.58)\end{array}$ & 6.38 & $\begin{array}{c}.041^{*} \\
\text { ST > SS }\end{array}$ \\
\hline CAPEp & $31.16 \pm 5.78$ & $\begin{array}{l}29.45 \pm 6.34 \\
(33.00)\end{array}$ & $\begin{array}{l}30.73 \pm 4.23 \\
(41.92)\end{array}$ & $\begin{array}{r}33.96 \\
(54.46)\end{array}$ & 11.07 & $\begin{array}{c}.004 * * \\
\mathrm{AD}>\mathrm{SS}\end{array}$ \\
\hline Fluency & $26.28 \pm 11.57$ & $\begin{array}{l}25.03 \\
(39.61)\end{array}$ & $\begin{array}{l}25.08 \pm 9.47 \\
(41.67)\end{array}$ & $\begin{array}{r}29.29 \\
(45.65)\end{array}$ & 0.88 & .64 \\
\hline Unique responses & $9.86 \pm 6.83$ & $\begin{array}{l}9.97 \pm 7.63 \\
(40.89)\end{array}$ & $\begin{array}{l}5.04 \pm 10.63 \\
(42.13)\end{array}$ & $\begin{array}{r}7.50 \pm 9.86 \\
(43.38)\end{array}$ & 0.15 & .93 \\
\hline $\begin{array}{l}\text { Proportion of } \\
\text { unique to total } \\
\text { responses }\end{array}$ & $0.36 \pm 0.13$ & $\begin{array}{l}0.37 \pm 0.13 \\
(43.52)\end{array}$ & $\begin{array}{l}0.35 \pm 0.14 \\
(41.63)\end{array}$ & $\begin{array}{r}0.34 \\
(40.31)\end{array}$ & 0.25 & .88 \\
\hline PBI & $0.031 \pm 0.38$ & $\begin{array}{l}0.033 \pm 0.40 \\
(42.32)\end{array}$ & $\begin{array}{l}0.058 \pm 0.36 \\
(43.56)\end{array}$ & $\begin{array}{l}-0.002 \pm 0.38 \\
(39.88)\end{array}$ & 0.34 & .84 \\
\hline $\begin{array}{l}\text { Context } \\
\text { Adaptation }\end{array}$ & $0.057 \pm 0.054$ & $\begin{array}{l}0.062 \pm 0.054 \\
(44.45)\end{array}$ & $\begin{array}{l}0.058 \pm 0.049 \\
(42.85)\end{array}$ & $\begin{array}{r}0.052 \pm 0.060 \\
(37.71)\end{array}$ & 1.14 & .57 \\
\hline
\end{tabular}

Note. $\mathrm{AQ}=$ Autism Quotient; CAPEp = Positive scale of the Community Assessment of Psychic Experiences; IQ $(\mathrm{fNART})=$ Intelligence Quotient estimated from the National Adult Reading Test-French version; PBI = Proactive Behavioral Index (positive values indicate proactive control bias, and negative values indicate reactive control bias); Context adaptation $=$ Variance in the Proportion of Unique to Total Responses; Fluency and Unique responses pertain to total responses across all four contexts. ${ }^{a}$ For all continuous variables, we report means and standard deviations and in parentheses the mean rank of the Kruskal-Wallis test (H). ${ }^{b}$ All pairwise comparisons of the continuous variables were adjusted by the Bonferroni correction for multiple tests. AQ total scores were higher for the Science and Tech compared to the Social Sciences students $\left(p_{c o r r}=0.038\right)$, and the CAPE-positive scores were higher for the Arts and Design compared to the Social Sciences students $\left(p_{\text {corr }}=0.003\right)$. The bold highlight values are significant effects. ${ }^{*} \mathrm{p}<.05,{ }^{* *} \mathrm{p}<.01$. 
provide descriptive details and internal consistency of the AQ and subscales (Table S1), and the correlations between the AQ subscales (Table S2).

\section{COMMUNITY ASSESSMENT OF PSYCHIC EXPERIENCES (CAPE-42)}

The CAPE consists for 42 self-report items, asking participants to indicate the frequency of their experiences on a 4-point Likert scale from never (1) to nearly always (4). For the purposes of this study, positive schizotypal personality traits were assessed with the 20-item positive subscale of CAPE-42 (CAPEp) (Konings, Bak, Hanssen, Van Os, \& Krabbendam, 2006). The total score, which can range from 20-80, was calculated by summing the frequency scores of the 20 items. The internal consistency of CAPEp in our study was adequate $(\alpha=0.75)$ and comparable to previously reported values (Brenner et al., 2007). In the Supplementary Information, we provide descriptive details and internal consistency of the CAPE- 42 and subscales (Table S3), and the correlations between the CAPE-42 subscales (Table S4).

\section{NATIONAL ADULT READING TEST-FRENCH VERSION (FNART)}

To control for intelligence which may play a role in divergent thinking (Benedek et al., 2014; Jauk et al., 2013; Nusbaum \& Silvia, 2011), full scale IQ was estimated with the fNART (Mackinnon \& Mulligan, 2005). The fNART consists of 40 words of irregular pronunciation. Participants were awarded one point for every correctly pronounced word. Using the total score, the full Wechsler Adult Intelligence Scale (WAIS) IQ was estimated as follows: WAIS-R IQ $=70.33+1.41$ x fNART (Mackinnon \& Mulligan, 2005).

\section{THE AX-CPT NO-GO VERSION}

Cognitive control was assessed with a no-go version of the AX-CPT task and administered with PEBL Version 2.0 Beta 3 program (Mueller \& Piper, 2014). Participants were asked to press the spacebar only when the letter $\mathrm{X}$ appeared immediately after an $\mathrm{A}$ and to withhold response to all other stimuli. The letter A represents a relevant cue or context that needs to be maintained in order to treat the target $\mathrm{X}$ or the goal information (Braver et al., 1999). The task also consisted of other letter stimuli, with B representing a random cue letter different from A, and Y representing a random probe letter different from X. Following Lee and Park (2006), the task (see Figure 1) consisted of 10 blocks of 20 letters with a brief break between each

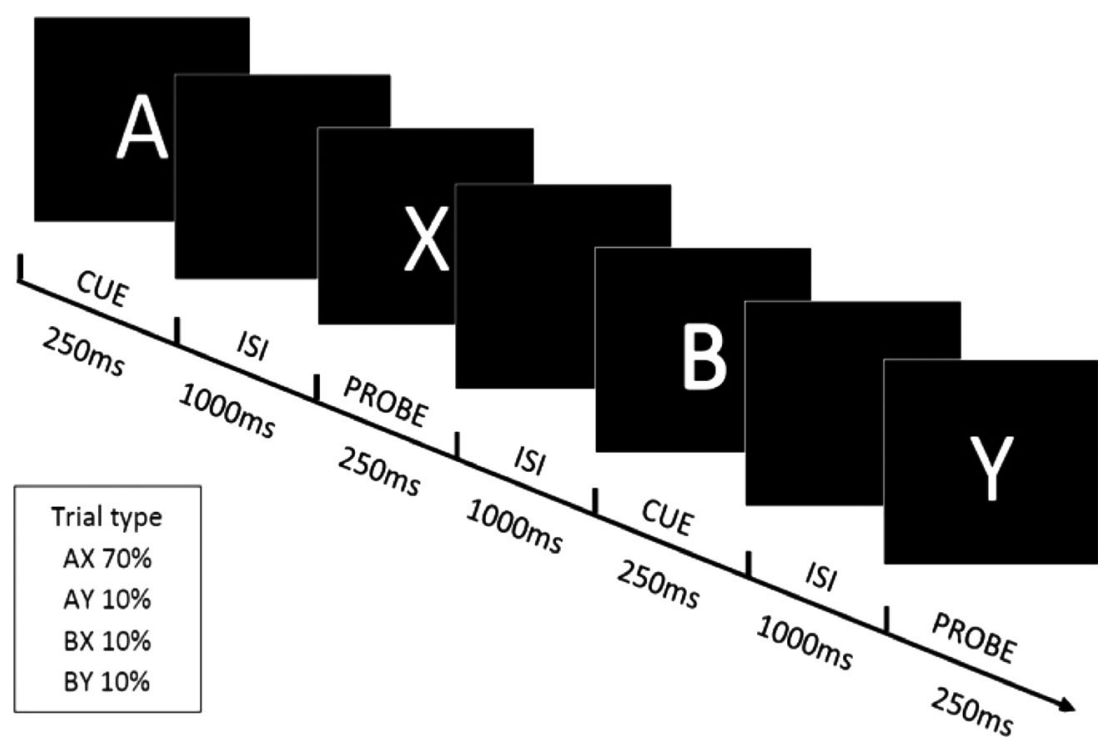

FIGURE 1. Illustration of the computerized AX-CPT task. White letters (cue or probe) are presented on a black background for $250 \mathrm{~ms}$, with an inter-stimulus interval (ISI) of 1,000 ms. B represents any cue different from $\mathrm{A}$, and $\mathrm{Y}$ any probe different from $\mathrm{X}$. AX trials appeared at a $70 \%$ frequency, and $\mathrm{AY}, \mathrm{BX}$, and $\mathrm{BY}$ trial types at 10\% each. 
block. Participants pressed the space bar to begin the next block. Every stimulus was presented for $250 \mathrm{~ms}$. The inter-stimulus interval was fixed at $1,000 \mathrm{~ms}$ in order to minimize time of cue maintenance, and so working memory assessment (Lee \& Park, 2006). The sequence AX had a probability of $70 \%$ and the remaining sequences (i.e., AY, BX, BY) $10 \%$ each. With a high probability of AX occurrences, participants were expected to develop a heightened tendency to respond to X (Lee \& Park, 2006). In this task, AY errors reflect an excessive maintenance of context, indicative of proactive control, whereas BX errors reflect a lack of context processing, indicative of reactive control (Barch, Carter, MacDonald, Braver, \& Cohen, 2003; Barch et al., 2004; Braver et al., 1999, 2009; Gonthier et al., 2016). Since we were interested in estimating reactive and proactive control tendencies, the Proactive Behavioural Index (PBI) (Braver et al., 2009) was computed as follows: $(\mathrm{AY}-\mathrm{BX}) /(\mathrm{AY}+\mathrm{BX})$. A log-linear correction was applied when errors equaled zero as follows: (number of errors +0.5 /frequency of trials +1 ). A positive PBI score indicated a bias for proactive control, whereas a negative PBI score indicated a bias for reactive control.

\section{THE DRAWING TASK}

A drawing task (see Figure 2) was created to assess non-verbal divergent thinking across contexts. This task was based on the figural creativity test of Torrance (Torrance Tests of Creative Thinking (TTCT); Torrance, 1974), which required participants to draw objects from lines or circles. We developed a figural test in order to assess a non-verbal form of idea generation and to be able to use it more widely without language barriers. Our drawing task consisted of three basic geometric shapes: a circle, a square, and a triangle. Each participant was allocated a shape according to a fixed turnover and was asked to draw as many objects as possible using the allocated shape (i.e., objects containing or having this shape) on an A4 blank sheet. In contrast to the original TTCT task, in which participants were not restricted to a particular context, in our task, participants were asked to draw their objects in four different predetermined contexts, which were presented in a fixed order as follows: school, forest, warehouse, and festival. These contexts correspond to various contextual conditions: closed/social (school), open/nonsocial (forest), closed/nonsocial (warehouse), and open/social (festival) and were chosen to maximize contextual shifts and variation (see section Context variation of the drawing task of the results section).

Drawing time within each context was limited to three minutes. Participants were instructed to draw as many objects as they can during three minutes in the given context and that the quality of the drawing was not important. In addition, participants were asked to number every drawing, and at the end of each drawing period, they were asked to highlight in color the shape in the drawing and to name every object drawn. This was done in order to ensure that participants understood the instructions and to avoid subjectivity in object identification. Following naming of objects, participants were asked to immediately move to the following context.

Divergent thinking was assessed under conditions requiring the participant to perform under constraints imposed by the allocated shape and the given context. As such, the task embodies the necessary conditions to assess the participants' potential in the generation of original and unique ideas, within and across contexts (Lubart et al., 2015; Nijstad et al., 2010). As recommended by Plucker, Qian, and Wang (2011), the participant's creative potential was estimated as the proportion of unique responses to the total responses in each context, in order to account for the potential confound of fluency. Unique responses were regarded as those responses that appeared only once in the entire pool of responses produced by the entire study sample. Shapes that were not transformed into objects were excluded. The first author who ran the experiment rated the divergent thinking task for the total number of responses and the total number of unique responses in every context. The intra-class correlation coefficients for the total $($ ICC $=.92)$ and unique (ICC $=.83$ ) responses across the four contexts suggested that the intrarater reliability was high.

Since we were specifically interested in how well participants performed when shifting to new contexts, context adaptation of divergent thinking was then conceptualized as the variance in the proportion of unique to total responses across the four contexts (henceforth, Context Adaptation). Importantly, we assumed that a lower variance from one context to another would indicate better context adaptation of divergent thinking. See supplementary information (Tables S5-S7) for a summary of the other task results.

\section{PROCEDURE}

In a quiet room, and after a brief explanation of the study, participants signed the consent form and completed a brief demographics questionnaire. Participants then performed the drawing task and then the AX-CPT. This was followed by the AQ, fNART, and CAPE-42. All participants performed the task and 

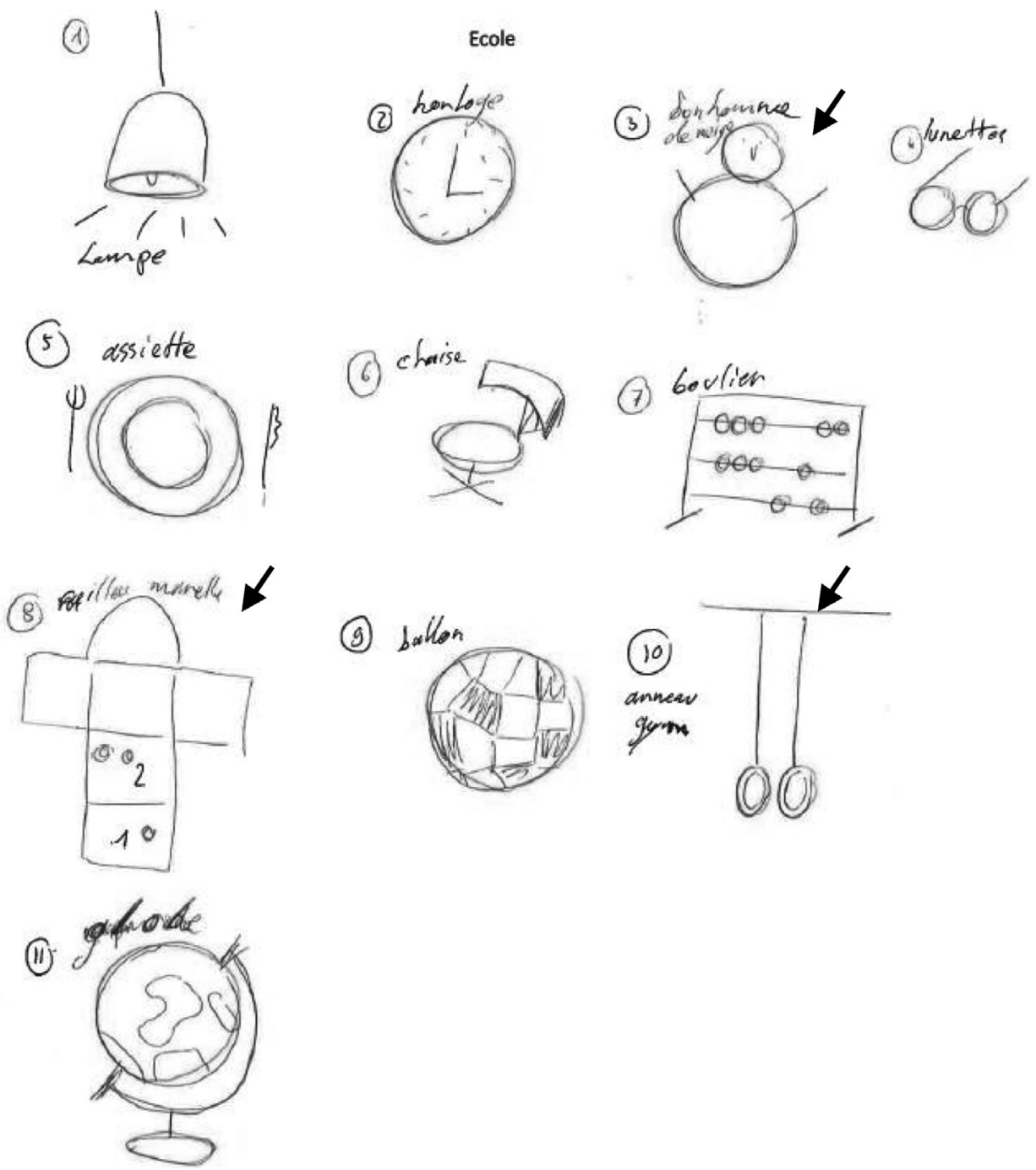

FIGURE 2. Sample performance from the drawing task. This figure shows the objects drawn by a participant with a circle as the basic shape, in the context of a school. The participant numbered every object while drawing. At the end of the three-minute drawing period, the participant highlighted in red the shape and named every object, which were noted by the experimenter. Indicated in black arrows, drawings number 3 (snowman), 8 (hopscotch), and 10 (gymnastics rings) are unique.

completed the questionnaires in the same order. The entire session lasted about 40 minutes. Participants did not receive any remuneration for taking part in the study. A written informed consent was obtained from each participant, and all experiments were conducted in accordance with ethics ordinances of the University of Lausanne and the Helsinki Declaration. Only French native speakers were enrolled in the study. 


\section{STATISTICAL ANALYSES}

First, we performed repeated measures of variance on the proportion of unique to total responses to test if we were successful in inducing variation across the four contexts of the task. Next, since the distribution of context adaptation was right skewed $(\mathrm{SD}=+1.72)$, we used Spearman's rho to determine its relationship with demographic variables and tasks performance measures. Kruskal-Wallis tests were used to examine differences between shapes, universities, and sex. We then ran a regression analysis that factorially examined (i.e., all possible main effects and interactions) the effect of the standardized scores of PBI, autistic, and positive schizotypal traits on context adaptation. The analysis was conducted using generalized linear models with a log-link function and robust estimation. The effect size of the regression model was calculated in terms of Pseudo $R^{2}$ using the following formula: Pseudo $R^{2}=1$-(Deviance/Null Deviance). Since we were interested in how autistic and positive schizotypal traits moderated the relationship between PBI and of context adaptation, interaction terms were probed by estimating if the regression slopes of the predictor PBI were different from zero at different levels of the moderator variables (i.e., at $-1 \mathrm{SD}$, at the Mean, and at $+1 \mathrm{SD})$. It is noteworthy that this interaction probe procedure does not involve splitting the sample into smaller groups using these cutoff points. Rather, it estimates the effect of a predictor on the dependent variable, while holding constant the other predictor at a discrete point. Accordingly, this approach allows us to infer from the model the effect of discrete levels of autistic and positive schizotypal traits on context adaptation within the entire sample. Where applicable, p-values were adjusted by the Bonferroni correction method for multiple tests.

\section{RESULTS}

SAMPLE CHARACTERISTICS

Table 1 reports the characteristics of the overall sample and of the participants of each of the universities. Differences were observed in gender distribution, AQ total scores, and CAPE-positive scores.

\section{CONTEXT VARIATION OF THE DRAWING TASK}

The repeated measures analysis of variance revealed that the proportion of unique to total responses across the four task contexts (school, forest, warehouse, and festival) was significant $(F(3,246)=5.53$, $\left.p=.001, \eta_{\mathrm{p}}{ }^{2}=0.063\right)$, which confirms that our task was successful in inducing considerable response variation across the four contexts. See Table S7 for the mean and standard deviations of the proportion of unique responses in the four contexts.

\section{CONTEXT ADAPTATION}

First, Spearman's rho did not reveal any significant association between context adaptation and age, years of formal education, or IQ $\left(-0.180<r_{s}<.070 ; p_{\mathrm{s}}>.330\right)$. Moreover, Kruskal-Wallis tests did not reveal any significant differences in context adaptation between shapes $(\mathrm{H}=5.990, d f=81, p=.050)$, universities $(\mathrm{H}=1.14, d f=81, p=.57)$, or $\operatorname{sex}(\mathrm{H}=0.39, d f=82, p=.53)$. Considering the absence of significant results, we did not control for these variables in the regression model. Moreover, Spearman's rho between the main variables of the model (Table 2) revealed a positive significant association between autistic and positive schizotypal traits. There were also significant negative correlations between positive schizotypal traits and cognitive control (PBI) and between cognitive control and context adaptation, such that increasing proactive control tendencies were associated with lower positive schizotypal traits and better context adaptation (i.e., lower variance). Moreover, better context adaptation was associated with increased overall (across all contexts) fluency and unique responses.

Next, the omnibus test of the regression model was significant $\left(\chi^{2}=16.00, d f=7, p=.025\right.$, pseudo $R^{2}=0.176$ ), explaining $17.6 \%$ of the variance. Results of the regression analysis (see Table 3 ) revealed a significant negative interaction of autistic traits and positive schizotypal traits, as well as of autistic traits and PBI on context adaptation. However, these interactions were qualified by a 3-way interaction of PBI, autistic traits, and positive schizotypal traits. Therefore, the results are interpreted in terms of this 3-way interaction.

The probe of the 3-way interaction (see Table 4 and Figure 3 ) revealed that the association of PBI with context adaptation was significantly positive when autistic traits were relatively low and positive schizotypal traits were relatively high (Figure 3c, light gray line). In contrast, the association of PBI with context adaptation was significantly negative when both autistic and positive schizotypal traits were relatively high (Figure 3c, black line). 


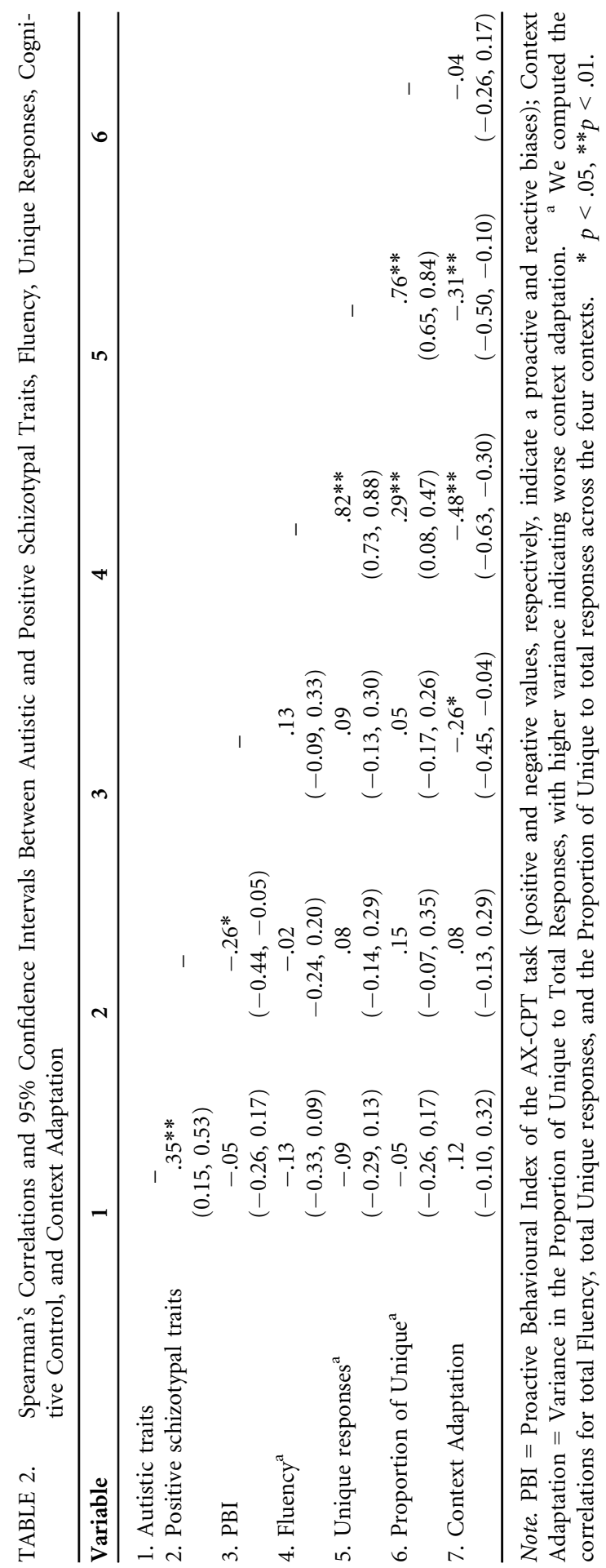


TABLE 3. Summary of Regression Model Examining the Effect of Cognitive Control, Autistic, and Positive Schizotypal Traits on Context Adaptation ${ }^{\mathrm{a}}$

\begin{tabular}{|c|c|c|c|c|c|}
\hline Variables & B $(95 \%$ CI $)$ & $S E$ & $\begin{array}{l}\text { Wald's } \\
\chi^{2}\end{array}$ & $d f$ & $p$-value \\
\hline Autistic traits & $-0.20(-0.164,0.143)$ & 0.080 & 0.07 & 1 & .799 \\
\hline Positive schizotypal traits & $0.056(-0.131,0.225)$ & 0.089 & 0.40 & 1 & .527 \\
\hline PBI & $-0.050(-0.534,0.272)$ & 0.078 & 0.41 & 1 & .524 \\
\hline Autistic traits $\mathrm{x}$ Positive schizotypal traits & $-0.186(-0.273,-0.068)$ & 0.051 & 13.13 & 1 & $<.001 * *$ \\
\hline PBI x Autistic traits & $-0.116(-0.609,-0.002)$ & 0.059 & 3.89 & 1 & $.048^{*}$ \\
\hline PBI x Positive schizotypal traits & $0.114(-0.085,0.689)$ & 0.075 & 2.34 & 1 & .126 \\
\hline $\begin{array}{l}\text { PBI x Autistic traits x Positive schizotypal } \\
\text { traits }\end{array}$ & $-0.191(-0.763,-0.246)$ & 0.050 & 14.66 & 1 & $<.001 * *$ \\
\hline
\end{tabular}

Note. PBI $=$ Proactive Behavioural Index (positive values indicate proactive control bias, and negative values indicate reactive control bias); ${ }^{*} p<.05 ;{ }^{* *} p<.001{ }^{a}$ Context adaptation $=$ Variance in the Proportion of Unique to Total Responses The bold highlight values are significant effects.

TABLE 4. Summary of the Moderating Effects of Autistic and Positive Schizotypal Traits on the Effect of PBI on Context Adaptation

\begin{tabular}{lllccc}
\hline Level of Moderators $^{\mathbf{a}}$ & \multicolumn{1}{c}{ B } & $\boldsymbol{S E}$ & $\boldsymbol{t}(\boldsymbol{d} \boldsymbol{f}=\mathbf{8 1})$ & $\boldsymbol{p}$-value & Cohen's $\boldsymbol{d}$ \\
\hline Low PS / Low AT & -0.011 & 0.006 & -1.85 & .068 & .41 \\
Low PS / Average AT & -0.009 & 0.006 & -1.52 & .133 & .34 \\
Low PS / High AT & -0.006 & 0.006 & -0.96 & .340 & .21 \\
Average PS / Low AT & 0.004 & 0.006 & 0.65 & .521 & .14 \\
Average PS / Average AT & -0.003 & 0.006 & -0.49 & .628 & .11 \\
Average PS / High AT & -0.010 & 0.006 & -1.59 & .115 & .35 \\
High PS / Low AT & $\mathbf{0 . 0 2 9}$ & $\mathbf{0 . 0 0 8}$ & $\mathbf{3 . 8 1}$ & $<\mathbf{0 . 0 0 1 * *}$ &. $\mathbf{8 5}$ \\
High PS / Average AT & 0.004 & 0.006 & 0.65 & .520 & .14 \\
High PS / High AT & $-\mathbf{0 . 0 1 2}$ & $\mathbf{0 . 0 0 6}$ & $\mathbf{- 2 . 0 4}$ & $\mathbf{. 0 4 5}$ & $\mathbf{. 4 5}$ \\
\hline
\end{tabular}

Note. $\quad{ }^{\text {a }}$ PS = Positive Schizotypy; AT = Autistic Traits; Low, average, and high levels of the moderator variables corresponded to $-1 \mathrm{SD}$ from the mean, the mean, and $+1 \mathrm{SD}$ from the mean. Effect sizes are reported in terms of the absolute values of Cohen's $d$. The bold highlight values are significant effects. $\quad * p<.05$; $*^{* *} p<.001$.

\section{EXPLORATORY ANALYSES}

In order to further investigate which of the AQ domains were most relevant in the 3-way interaction, we performed similar analyses for each of the subscales in 5 separate regression models. The results showed that only the model containing attention switching - where higher scores indicate increased focus of attentionwas significant $\left(\chi^{2}=15.82, d f=7, p=.035\right.$, pseudo $\left.R^{2}=.324\right)$, explaining $32.4 \%$ of the variance (see Table S8 for complete summary of the regression model). Importantly, parameter estimates revealed that the 3-way interaction between PBI $\mathrm{x}$ Positive Schizotypy $\times$ Attention Switching was significant $(B$ $(S E)=-.125(.059)$, Wald's $\chi^{2}=4.46, p=.035$ ). The probe of the 3 -way interaction (see Figure 4 ) revealed that when focus of attention was relatively high the association of PBI with context adaptation was significant and progressively more negative with increasing levels of positive schizotypal traits (Figure 4a-c, black line, Table S9). In contrast, we see that the association of PBI with context adaptation was significantly positive when focus of attention was relatively low and positive schizotypal traits were relatively high (Figure $4 \mathrm{c}$, light gray line). 

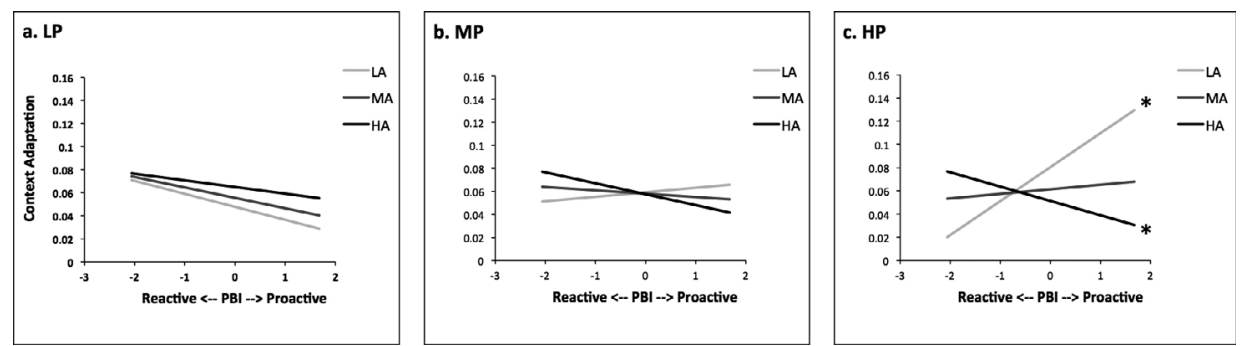

FIGURE 3. The moderating effect of autistic and positive schizotypal traits on the association between the Proactive Behavioural Index (PBI) and Context Adaptation (i.e., Variance in the Proportion of Unique to Total Responses). Lower variance values indicate better context adaptation of divergent thinking, and a shift from negative to positive PBI values represents a shift from reactive to proactive control tendencies. Panel a shows the association of PBI with context adaptation when positive schizotypal traits are low (LP) and autistic traits are low (LA, light gray line), average (MA, gray line), and high (HA, black line). Panel b shows the association of PBI with context adaptation when positive schizotypal traits are average (MP) and autistic traits are low (LA, light gray line), average (MA, gray line), and high (HA, black line). Panel c shows the association of PBI with context adaptation when positive schizotypal traits are high (HP) and autistic traits are low (LA, light gray line), average (MA, gray line), and high (HA, black line). ${ }^{*} p<.05$.
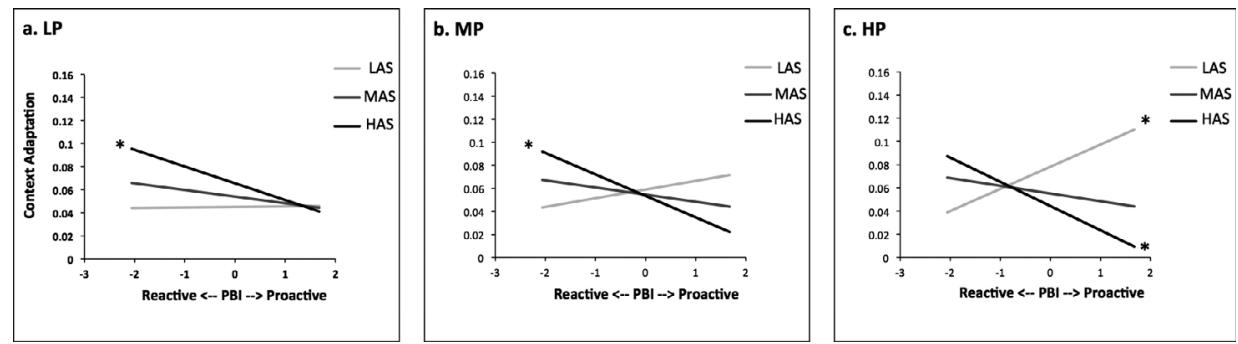

FIGURE 4. The moderating effect of attention switching (AS; or increased focus of attention) and positive schizotypal traits on the association between the Proactive Behavioural Index (PBI) and Context Adaptation (i.e., Variance in the Proportion of Unique to Total Responses). Lower variance values indicate better context adaptation of divergent thinking, and a shift from negative to positive PBI values represents a shift from reactive to proactive control tendencies. Panel a shows the association of PBI with context adaptation when positive schizotypal traits are low (LP) and focus of attention is low (LAS, light gray line), average (MAS, gray line), and high (HAS, black line). Panel $\mathrm{b}$ shows the association of PBI with context adaptation when positive schizotypal traits are average (MP) and focus of attention is low (LAS, light gray line), average (MAS, gray line), and high (HAS, black line). Panel c shows the association of PBI with context adaptation when positive schizotypal traits are high (HP) and focus of attention is low (LAS, light gray line), average (MAS, gray line), and high (HAS, black line). ${ }^{*} p<0.05$.

\section{DISCUSSION}

The study aimed to investigate (a) the association between cognitive control and context adaptation of divergent thinking and (b) the modulatory role of autistic and positive schizotypal traits on this association. We first hypothesized an association between cognitive control and context adaptation of divergent thinking. This hypothesis was confirmed such that increased proactive control, as indexed by the Proactive Behavioral Index (PBI) of the AX-CPT task, was associated with better context adaptation, indexed by lower variance in the proportion of unique to total responses across contexts. This suggests that proactive control is related 
to the ability to generate unique ideas across contexts and which could reflect the greater ability of individuals to maintain focus while working on a creative thinking task (Zabelina \& Robinson, 2010). Importantly, however, the association between context adaptation of divergent thinking and cognitive control, as predicted by our second hypothesis, was moderated by the relative expression of autistic and positive schizotypal traits. Specifically, the probe of the 3-way interaction of cognitive control, autistic and positive schizotypal traits revealed that context adaptation improved with (a) increasing reliance on reactive control when autistic traits were low and positive schizotypal traits were high and (b) with increasing proactive control and especially when both autistic and positive schizotypal traits were concurrently high. These results demonstrate that while both cognitive control strategies are conducive to context adaptation of divergent thinking, the benefit they confer on context adaption appears to depend on the individual's specific profile of autistic and positive schizotypal traits.

These results provide insights regarding the effect of the relative expression of autistic and positive schizotypal traits on the association between cognitive control strategy and the generation of creative divergent ideas across contexts. For the purpose of generating unique divergent ideas across contexts, individuals with high positive schizotypal traits appear to benefit from a reactive control strategy (see Figure 3c), which is also evident in the negative association of proactive control and positive schizotypal traits (see Table 2). Similar to individuals with schizotypal personality disorder (Barch et al., 2004), individuals with high positive schizotypal traits may exhibit less than optimal capacity in constructing and maintaining context representation. This implies that representation of contextually relevant information may only be encoded temporarily. Thus, reactive control may enable them to cope with this deficit by processing information without maintaining context representation, but which is reactivated with newly presented information or contexts. This dovetails with evidence linking reactive control to diminished working memory capacity (Gonthier et al., 2019), which has also been found to be associated with positive schizotypy (Matheson \& Langdon, 2008; Schmidt-Hansen \& Honey, 2009). We can, therefore, think of reactive control as an adaptive strategy for individuals with high positive schizotypal traits that enables them to manifest their creative potential in various contexts.

However, it is important to also note, as is also evident from Figures $3 \mathrm{c}$ and $4 \mathrm{c}$, that a shift from reactive to proactive control strategy greatly diminishes the ability of individuals with high positive schizotypal traits to flexibly generate unique ideas across contexts. This is consistent with research in patients with schizophrenia (Boudewyn, Scangos, Ranganath, \& Carter, 2020; Lesh et al., 2013) and neurotypicals with high positive schizotypal traits (Abu-Akel et al., 2018) who exhibited a decline in performance in tasks requiring proactive compared to reactive control. The notion of latent inhibition - the inability to filter out previously experienced events or contexts as irrelevant-which is considered an endophenotype of schizotypy (Lubow \& Gewirtz, 1995) and specifically positive schizotypy (Schmidt-Hansen et al., 2009), might help explain the uneven performance of these individuals across contexts when deploying a proactive control strategy. Thus, it is conceivable that the retention of information from the previous context, which is now irrelevant for the new context, might interfere with performance in the new context. Taken together, this suggests that creativity tasks that induce or are inherently biased toward proactive control may put individuals with high positive schizotypal traits at a disadvantage, particularly when shifting contexts is required.

Our main analysis also revealed that proactive control can facilitate context adaptation in people who are also high on both autistic and positive schizotypal traits, such that when positive schizotypal traits are high, proactive control improved context adaptation with increasing autistic traits (see Figure 3c). However, the exploratory analyses revealed that the role of autistic traits in explaining the relationship between context adaptation and cognitive control is more nuanced and appears specific to the attention-switching domain, suggesting that proactive control is associated with better context adaption in individuals with high focus of attention (see Figure 4a), and which was further enhanced in those with increasing levels of positive schizotypal traits (Figure $4 \mathrm{a}-\mathrm{c}$ ), as evident by the increase in effect sizes (see Table S9). This is consistent with the suggestion that increased focus of attention affords the individual the ability to optimize the deployment of proactive control by minimizing interference from internal or external sources of distraction (Braver, 2012). Notably, these results also suggest that unlike reactive control, which appears to facilitate context adaptation in individuals with high positive schizotypy and low focus of attention (Figure 4c), proactive control facilitates context adaptation in individuals with low positive schizotypy and high focus of attention (Figure 4a). This is consistent with previous research suggesting that individuals with contrasting autistic and positive schizotypy trait profiles appear to be differentially reliant on proactive versus reactive control strategies (Abu-Akel et al., 2018; Niendam et al., 2014; Spaniol et al., 2018). 
Taken together, the above findings suggests that both reactive and proactive control can facilitate context adaptation, albeit by activating different mechanisms. As stated above, proactive control facilitates context adaptation by monitoring the context and maintaining task relevant information over a sustained period of time, while reactive control facilitates context adaptation by processing current contextual information and without relying on previously constructed contextual cues. While different, we contend that both strategies converge on minimizing interference with the successful completion of the goal, which is one reason why both cognitive control strategies are conducive to context adaptation. Under proactive control, interference is minimized by focus of attention, which substantially reduces the availability of externally distracting information or irrelevant information that could be held in working memory. In contrast, under reactive control, interference is minimized by inhibiting previously held representations from interfering with newly construed goals or contexts. It has been suggested that the use of reactive and proactive control might be related to working memory capacity (Gonthier et al., 2019). It would be interesting to know in future studies how interference reduction might interact with working memory capacity in facilitating context adaption.

Moreover, the finding regarding improved context adaptation in people who are high on both autistic and positive schizotypal traits (see Figures $3 \mathrm{c}$ and $4 \mathrm{c}$ ) is consistent with previous research showing that autistic and positive schizotypal traits interactively improved perspective-taking abilities (Abu-Akel et al., 2015), social and executive functioning (Shi et al., 2017), and reduced interference from salient distractors (Abu-Akel, Apperly, Wood, Hansen, \& Mevorach, 2017). Thus, it may not be serendipitous that the combination of such phenotypes (i.e., co-occurring autism and psychosis) has been proposed to explain the genius of Beethoven, Newton, and Nash (Badcock, 2009). But how does the concurrent presence of high autistic and high positive schizotypal traits render proactive control more beneficial to context adaptation? It can be speculated that the co-presence of these traits make possible for the individual to tap both systematic and flexible processing modes within and across contexts (see Nijstad et al., 2010), which are, respectively, afforded by proactive and reactive control (Appelbaum, Boehler, Davis, Won, \& Woldorff, 2014). Since the correlation analyses in our study showed only support for the association between positive schizotypal traits and reactive control tendencies, the contribution of increasing autistic traits to improvement in context adaptation under proactive control remains unresolved. However, if individuals with high schizotypal traits are similar to patients with schizophrenia in that they can engage reactive but not proactive control mechanisms (Lesh et al., 2013), the co-presence of autistic traits, which has been associated with greater utilization of proactive control strategies (Spaniol et al., 2018), appears to somehow restore the ability for these individuals to flexibly engage proactive control. It should be noted, however, that while healthy participants are expected to flexibly engage these modes of cognitive control (Marklund \& Persson, 2012), our results suggest that this might be maximally present among individuals in whom both high levels of autistic and positive trait dimensions are co-present.

Our results may have implications to theories of creativity. While these theories are in agreement that both automatic and effortful/controlled processes are both involved in the creative process (Beaty et al., 2016; Nijstad et al., 2010; Sowden et al., 2015; Zabelina \& Robinson, 2010; Zhang et al., 2020), they remain uncertain as to the relative contribution (or utilization) of these processes. Our results support the relevance of both automatic (reactive) and controlled (proactive) processes for context adaptation of divergent thinking, but also provide novel insight suggesting that the engagement of these processes depend on the relative combination of autistic and positive schizotypal traits within the individual.

Our findings should be considered in light of a number of limitations. First, the sample consisted of students only and thus may not be representative of the general population. However, by sampling from different universities and fields of study, in which certain traits are clearly more represented (see Table 1), the distribution of these traits in our overall sample might approximate their distribution within the general population (see Sampson et al., 2020). Second, the results of the context adaptation task may be limited by the instructions, which did not explicitly ask participants to draw creative objects, but to draw as many objects as possible. Such explicit instructions have been shown to enhance participants' tendency to generate creative ideas (Nusbaum, Silvia, \& Beaty, 2014). Third, while our task has not been previously validated, the results show that the task is sensitive to subtle variation in personality traits and cognitive control and, thus, is potentially a useful new tool for research concerned with the role of context adaptation in creativity. Fourth, these results may be limited by the single rater assessment of the task; however, our criteria for ascertaining fluency (total number of responses) and identifying the unique responses were considered straightforward enough not to require more than one rater, which is also evident by the high intrarater reliability. Fifth, while the task has the advantage of not relying on language abilities, the results may not be 
generalizable to all test environments. Future research may explore our operationalization of context adaptation using other figural and language-based divergent/creative thinking tests. Sixth, a replication of our research would be enhanced by the inclusion of a measure of working memory capacity, since it has been associated with reactive control (Gonthier et al., 2019), positive schizotypy (Matheson \& Langdon, 2008; Schmidt-Hansen \& Honey, 2009), and creative thinking (Rominger et al., 2011, 2019). Finally, our study has examined how divergent thinking fluctuates with change in context. However, creativity involves both convergent and divergent thinking (Cropley, 2006; Guilford, 1950), which have respectively been associated with autistic and positive schizotypal tendencies (Abu-Akel et al., 2020; Claridge \& McDonald, 2009; Webb, Little, Cropper, \& Roze, 2017). Assessing the interaction between cognitive control, autistic, and positive schizotypal traits on how convergent thinking fluctuates with change in context would be an important next step.

\section{CONCLUSION}

To our knowledge, this study is the first to investigate the interplay between cognitive control, autistic, and positive schizotypal traits on the ability to produce divergent ideas across contexts. Our results suggest that both reactive and proactive cognitive control mechanisms can facilitate context adaptation of divergent thinking. However, we show that this depends on the specific combination of autistic and positive schizotypal traits within the individual, with reactive control benefiting those with a predominant-positive schizotypal profile, and proactive control predominantly benefiting those who are high on both autistic and positive schizotypal traits. To the extent divergent thinking is an estimate of one's creative potential (Runco \& Acar, 2012), this suggests that creative individuals, endowed with specific personality trait profiles, can deploy their cognitive control system in a context-sensitive manner (see also Zabelina \& Robinson, 2010). To make further progress in understanding variability in the human creative thinking process, it will be necessary to measure the impact of inducing different cognitive control strategies in individuals with various autistic and positive schizotypal phenotypic combinations. This would contribute to answering one of Guilford's (1950) long-standing questions: How can we promote the development of creative personalities? The present study highlights the utility and potential of such an approach.

The authors declare no conflict of interest.

\section{CONFLICT OF INTEREST}

\section{DATA AVAILABILITY STATEMENT}

Data can be obtained from the corresponding author upon a reasonable request.

\section{REFERENCES}

Abu-Akel, A., Apperly, I., Spaniol, M.M., Geng, J.J., \& Mevorach, C. (2018). Diametric effects of autism tendencies and psychosis proneness on attention control irrespective of task demands. Scientific Reports, 8(1), https://doi.org/10.1038/s41598-018-268217

Abu-Akel, A., Apperly, I.A., Wood, S.J., Hansen, P.C., \& Mevorach, C. (2017). Autism tendencies and psychosis proneness interactively modulate saliency cost. Schizophrenia Bulletin, 43(1), 142-151. https://doi.org/10.1093/schbul/sbw066

Abu-Akel, A., Webb, M.E., de Montpellier, E., Von Bentivegni, S., Luechinger, L., Ishii, A., \& Mohr, C. (2020). Autistic and positive schizotypal traits respectively predict better convergent and divergent thinking performance. Thinking Skills and Creativity, 36, 100656. https://doi.org/10.1016/j.tsc.2020.100656

Abu-Akel, A.M., Wood, S.J., Hansen, P.C., \& Apperly, I.A. (2015). Perspective-taking abilities in the balance between autism tendencies and psychosis proneness. Proceedings of the Royal Society B, 282(1808), 20150563. https://doi.org/10.1098/rspb.2015. 0563

Acar, S., Chen, X., \& Cayirdag, N. (2018). Schizophrenia and creativity: A meta-analytic review. Schizophrenia Research, 195, $23-31$. https://doi.org/10.1016/j.schres.2017.08.036

Appelbaum, L.G., Boehler, C.N., Davis, L.A., Won, R.J., \& Woldorff, M.G. (2014). The dynamics of proactive and reactive cognitive control processes in the human brain. Journal of Cognitive Neuroscience, 26(5), 1021-1038. https://doi.org/10.1162/jocn_a_ 00542

Badcock, C. (2009). The imprinted brain: How genes set the balance between autism and psychosis. Jessica Kingsley Publishers.

Barch, D.M., Carter, C.S., MacDonald, A.W., Braver, T.S., \& Cohen, J.D. (2003). Context-processing deficits in schizophrenia: Diagnostic specificity, 4-week course, and relationships to clinical symptoms. Journal of Abnormal Psychology, 112(1), 132-143. https://doi.org/10.1037/0021-843X.112.1.132

Barch, D.M., Mitropoulou, V., Harvey, P.D., New, A.S., Silverman, J.M., \& Siever, L.J. (2004). Context-processing deficits in schizotypal personality disorder. Journal of Abnormal Psychology, 113(4), 556-568. https://doi.org/10.1037/0021-843X.113.4.556 
Baron-Cohen, S., Wheelwright, S., Skinner, R., Martin, J., \& Clubley, E. (2001). The autism-spectrum quotient (AQ): Evidence from asperger syndrome/high-functioning autism, males and females, scientists and mathematicians. Journal of Autism and Developmental Disorders, 31(1), 5-17. https://doi.org/10.1023/A:1005653411471

Beaty, R.E., Benedek, M., Silvia, P.J., \& Schacter, D.L. (2016). Creative cognition and brain network dynamics. Trends in Cognitive Sciences, 20(2), 87-95. https://doi.org/10.1016/j.tics.2015.10.004

Benedek, M., Jauk, E., Sommer, M., Arendasy, M., \& Neubauer, A.C. (2014). Intelligence, creativity, and cognitive control: The common and differential involvement of executive functions in intelligence and creativity. Intelligence, 46, 73-83. https://doi. org/10.1016/j.intell.2014.05.007

Best, C., Arora, S., Porter, F., \& Doherty, M. (2015). The relationship between subthreshold autistic traits, ambiguous figure perception and divergent thinking. Journal of Autism and Developmental Disorders, 45(12), 4064-4073. https://doi.org/10.1007/ s10803-015-2518-2

Boudewyn, M.A., Scangos, K., Ranganath, C., \& Carter, C.S. (2020). Using prefrontal transcranial direct current stimulation (tDCS) to enhance proactive cognitive control in schizophrenia. Neuropsychopharmacology, 45(11), 1877-1883. https://doi.org/10.1038/ s41386-020-0750-8

Braver, T.S., Barch, D.M., \& Cohen, J.D. (1999). Cognition and control in schizophrenia: A computational model of dopamine and prefrontal function. Biological Psychiatry, 46(3), 312-328. https://doi.org/10.1016/S0006-3223(99)00116-X

Braver, T.S. (2012). The variable nature of cognitive control: A dual mechanisms framework. Trends in Cognitive Sciences, 16(2), 106-113.

Braver, T.S., Paxton, J.L., Locke, H.S., \& Barch, D.M. (2009). Flexible neural mechanisms of cognitive control within human prefrontal cortex. Proceedings of the National Academy of Sciences, 106(18), 7351-7356. https://doi.org/10.1073/pnas.0808187106

Brenner, K., Schmitz, N., Pawliuk, N., Fathalli, F., Joober, R., Ciampi, A., \& King, S. (2007). Validation of the English and French versions of the Community Assessment of Psychic Experiences (CAPE) with a Montreal community sample. Schizophrenia Research, 95(1-3), 86-95. https://doi.org/10.1016/j.schres.2007.06.017

Carlsson, I., Wendt, P.E., \& Risberg, J. (2000). On the neurobiology of creativity. Differences in frontal activity between high and low creative subjects. Neuropsychologia, 38(6), 873-885.

Claridge, G., \& McDonald, A. (2009). An investigation into the relationships between convergent and divergent thinking, schizotypy, and autistic traits. Personality and Individual Differences, 46(8), 794-799. https://doi.org/10.1016/j.paid.2009.01.018

Cohen, L.M. (2012). Adaptation and creativity in cultural context. Revista De Psicología, 30(1), 3-18.

Crespi, B., Leach, E., Dinsdale, N., Mokkonen, M., \& Hurd, P. (2016). Imagination in human social cognition, autism, and psychotic-affective conditions. Cognition, 150, 181-199. https://doi.org/10.1016/j.cognition.2016.02.001

Cropley, A. (2006). In praise of convergent thinking. Creativity Research Journal, 18(3), 391-404. https://doi.org/10.1207/s15326934c rj1803_13

Dai, D.Y., Tan, X., Marathe, D., Valtcheva, A., Pruzek, R.M., \& Shen, J. (2012). Influences of social and educational environments on creativity during adolescence: Does SES matter? Creativity Research Journal, 24(2-3), 191-199.

Ellamil, M., Dobson, C., Beeman, M., \& Christoff, K. (2012). Evaluative and generative modes of thought during the creative process. NeuroImage, 59(2), 1783-1794. https://doi.org/10.1016/j.neuroimage.2011.08.008

Faul, F., Erdfelder, E., Lang, A.-G., \& Buchner, A. (2007). G*Power 3: A flexible statistical power analysis program for the social, behavioral, and biomedical sciences. Behavior Research Methods, 39(2), 175-191. https://doi.org/10.3758/BF03193146

Feist, G.J. (2010). The function of personality in creativity. Kaufman, J.C. \& Sternberg, R.J., The Cambridge handbook of creativity, 113-140. Cambridge: Cambridge University Press. https://doi.org/10.1017/CBO9780511763205.009

Finke, R.A., Ward, T.B., \& Smith, S.M. (1992). Creative Cognition: Theory, Research and Applications. Cambridge, MA: MIT Press.

Fitzgerald, M., \& Lyons, V. (2013). Critical evaluation of the concept of autistic creativity. Recent Advances in Autism Spectrum Disorders, $I$. https://doi.org/10.5772/54465

Gonthier, C., Macnamara, B.N., Chow, M., Conway, A.R.A., \& Braver, T.S. (2016). Inducing proactive control shifts in the AXCPT. Frontiers in Psychology, 7. https://doi.org/10.3389/fpsyg.2016.01822

Gonthier, C., Zira, M., Colé, P., \& Blaye, A. (2019). Evidencing the developmental shift from reactive to proactive control in early childhood and its relationship to working memory. Journal of Experimental Child Psychology, 177, 1-16.

Groborz, M., \& Necka, E. (2003). Creativity and cognitive control: Explorations of generation and evaluation skills. Creativity Research Journal, 15(2-3), 183-197. https://doi.org/10.1080/10400419.2003.9651411

Guilford, J.P. (1950). Creativity. The American Psychologist, 5(9), 444-454.

Hurst, R.M., Nelson-Gray, R.O., Mitchell, J.T., \& Kwapil, T.R. (2007). The relationship of Asperger's characteristics and schizotypal personality traits in a non-clinical adult sample. Journal of Autism and Developmental Disorders, 37(9), 1711-1720. https://doi. org/10.1007/s10803-006-0302-z

Intasao, N., \& Hao, N. (2018). Beliefs about creativity influence creative performance: the mediation effects of flexibility and positive affect. Frontiers in Psychology, 9. https://doi.org/10.3389/fpsyg.2018.01810

Jankowska, D.M., Omelańczuk, I., Czerwonka, M., \& Karwowski, M. (2019). Exploring links between creative abilities, creative personality and subclinical autistic traits. Personality and Individual Differences, 142, 226-231. https://doi.org/10.1016/j.paid.2018. 05.008

Jauk, E., Benedek, M., Dunst, B., \& Neubauer, A.C. (2013). The relationship between intelligence and creativity: New support for the threshold hypothesis by means of empirical breakpoint detection. Intelligence, 41(4), 212-221.

Jung, R.E. (2014). Evolution, creativity, intelligence, and madness: "Here Be Dragons". Frontiers in Psychology, 5, 784. https://doi. org/10.3389/fpsyg.2014.00784 
Konings, M., Bak, M., Hanssen, M., Van Os, J., \& Krabbendam, L. (2006). Validity and reliability of the CAPE: A self-report instrument for the measurement of psychotic experiences in the general population. Acta Psychiatrica Scandinavica, 114(1), 55-61. https://doi.org/10.1111/j.1600-0447.2005.00741.x

Kowatari, Y., Lee, S.H., Yamamura, H., Nagamori, Y., Levy, P., Yamane, S., \& Yamamoto, M. (2009). Neural networks involved in artistic creativity. Human Brain Mapping, 30(5), 1678-1690.

LeBoutillier, N., Barry, R., \& Westley, D. (2014). The role of schizotypy in predicting performance on figural and verbal imagerybased measures of creativity. Creativity Research Journal, 26(4), 461-467. https://doi.org/10.1080/10400419.2014.961778

Lee, J., \& Park, S. (2006). The role of stimulus salience in CPT-AX performance of schizophrenia patients. Schizophrenia Research, 81(2-3), 191-197. https://doi.org/10.1016/j.schres.2005.08.015

Lesh, T.A., Westphal, A.J., Niendam, T.A., Yoon, J.H., Minzenberg, M.J., Ragland, J.D., ... Carter, C.S. (2013). Proactive and reactive cognitive control and dorsolateral prefrontal cortex dysfunction in first episode schizophrenia. NeuroImage: Clinical, 2, 590-599. https://doi.org/10.1016/j.nicl.2013.04.010

Lubart, T., Mouchiroud, C., Tordjman, S., \& Zenasni, F. (2015). Psychologie de la créativité-2e édition. Armand Colin.

Lubow, R.E., \& Gewirtz, J.C. (1995). Latent inhibition in humans: Data, theory, and implications for schizophrenia. Psychological Bulletin, 117, 87-103.

Ma, H.-H. (2009). The effect size of variables associated with creativity: a meta-analysis. Creativity Research Journal, 21(1), 30-42. https://doi.org/10.1080/10400410802633400

Mackinnon, A., \& Mulligan, R. (2005). Estimation de l'intelligence prémorbide chez les francophones. L'encéphale, 31(1), 31-43. https://doi.org/10.1016/S0013-7006(05)82370-X

Maddux, W.W., \& Galinsky, A.D. (2009). Cultural borders and mental barriers: The relationship between living abroad and creativity. Journal of Personality and Social Psychology, 96(5), 1047-1061. https://doi.org/10.1037/a0014861

Mäki-Marttunen, V., Hagen, T., \& Espeseth, T. (2019). Task context load induces reactive cognitive control: An fMRI study on cortical and brain stem activity. Cognitive Affective and Behavioral Neuroscience, 19(4), 945-965.

Marklund, P., \& Persson, J. (2012). Context-dependent switching between proactive and reactive working memory control mechanisms in the right inferior frontal gyrus. NeuroImage, 63(3), 1552-1560.

Matheson, S., \& Langdon, R. (2008). Schizotypal traits impact upon executive working memory and aspects of IQ. Psychiatry Research, 159(1-2), 207-214.

Mohr, C., \& Claridge, G. (2015). Schizotypy-Do Not Worry, It Is Not All Worrisome. Schizophrenia Bulletin, 41(suppl_2), S436S443. https://doi.org/10.1093/schbul/sbu185

Mueller, S.T., \& Piper, B.J. (2014). The Psychology Experiment Building Language (PEBL) and PEBL test battery. Journal of Neuroscience Methods, 222, 250-259. https://doi.org/10.1016/j.jneumeth.2013.10.024

Niendam, T.A., Lesh, T.A., Yoon, J., Westphal, A.J., Hutchison, N., Ragland, J.D., ... Carter, C.S. (2014). Impaired context processing as a potential marker of psychosis risk state. Psychiatry Research, 221(1), 13-20. https://doi.org/10.1016/j.pscychresns.2013. 09.001

Nijstad, B.A., Dreu, C.K.W.D., Rietzschel, E.F., \& Baas, M. (2010). The dual pathway to creativity model: Creative ideation as a function of flexibility and persistence. European Review of Social Psychology, 21(1), 34-77. https://doi.org/10.1080/ 10463281003765323

Nusbaum, E.C., \& Silvia, P.J. (2011). Are intelligence and creativity really so different? Fluid intelligence, executive processes, and strategy use in divergent thinking. Intelligence, 39(1), 36-45. https://doi.org/10.1016/j.intell.2010.11.002

Nusbaum, E.C., Silvia, P.J., \& Beaty, R.E. (2014). Ready, set, create: What instructing people to "be creative" reveals about the meaning and mechanisms of divergent thinking. Psychology of Aesthetics, Creativity, and the Arts, 8(4), 423-432. https://doi. org/10.1037/a0036549

O’Reilly, T., Dunbar, R., \& Bentall, R. (2001). Schizotypy and creativity: An evolutionary connection? Personality and Individual Differences, 31(7), 1067-1078. https://doi.org/10.1016/S0191-8869(00)00204-X

Plucker, J.A., Qian, M., \& Wang, S. (2011). Is Originality in the eye of the beholder? Comparison of scoring techniques in the assessment of divergent thinking. Journal of Creative Behavior, 45(1), 1-22. https://doi.org/10.1002/j.2162-6057.2011.tb01081.x

Robinson, K. (2011). Out of our minds: Learning to be creative. John Wiley \& Sons.

Rominger, C., Fink, A., Weiss, E.M., Bosch, J., \& Papousek, I. (2017). Allusive thinking (remote associations) and auditory topdown inhibition skills differentially predict creativity and positive schizotypy. Cognitive Neuropsychiatry, 22(2), $108-121$.

Rominger, C., Fink, A., Weiss, E.M., Schulter, G., Perchtold, C.M., \& Papousek, I. (2019). The propensity to perceive meaningful coincidences is associated with increased posterior alpha power during retention of information in a modified Sternberg paradigm. Consciousness and Cognition, 76, 102832.

Rominger, C., Weiss, E.M., Fink, A., Schulter, G., \& Papousek, I. (2011). Allusive thinking (cognitive looseness) and the propensity to perceive "meaningful" coincidences. Personality and Individual Differences, 51(8), 1002-1006. https://doi.org/10.1016/j.paid. 2011.08.012

Runco, M.A. (2004). Creativity. Annual Review of Psychology, 55(1), 657-687. https://doi.org/10.1146/annurev.psych.55.090902. 141502

Runco, M.A., \& Acar, S. (2012). Divergent thinking as an indicator of creative potential. Creativity Research Journal, 24(1), 66-75.

Runco, M.A., \& Pritzker, S.R. (1999). Encyclopedia of creativity. Academic Press.

Sampson, K.N., Upthegrove, R., Abu-Akel, A., Haque, S., Wood, S.J., \& Reniers, R. (2020). Co-occurrence of autistic and psychotic traits: implications for depression, self-harm and suicidality. Psychological Medicine, 1-9, https://doi.org/10.1017/ S0033291720000124. 
Schmidt-Hansen, M., \& Honey, R.C. (2009). Working memory and multidimensional schizotypy: Dissociable influences of the different dimensions. Cognitive Neuropsychology, 26(7), 655-670.

Schmidt-Hansen, M., Killcross, A.S., \& Honey, R.C. (2009). Latent inhibition, learned irrelevance, and schizotypy: Assessing their relationship. Cognitive Neuropsychiatry, 14(1), 11-29.

Shi, L.J., Liu, W.H., Shi, H.S., Yan, C., Wang, Y., Wang, Y., ... Chan, R.C. (2017). Co-occurrence of autistic and schizotypal traits and its association with emotional and psychosocial function in Chinese college students. Psychiatry Research, 248, 64-70. https://doi.org/10.1016/j.psychres.2016.12.021

Sierro, G., Rossier, J., \& Mohr, C. (2016). Validation of the French Autism Spectrum Quotient scale and its relationships with schizotypy and Eysenckian personality traits. Comprehensive Psychiatry, 68, 147-155. https://doi.org/10.1016/j.comppsych.2016. 03.011

Sowden, P.T., Pringle, A., \& Gabora, L. (2015). The shifting sands of creative thinking: Connections to dual-process theory. Thinking and Reasoning, 21(1), 40-60.

Spaniol, M.M., Shalev, L., \& Mevorach, C. (2018). Reduced distractor interference in neurotypical adults with high expression of autistic traits irrespective of stimulus type. Autism Research, 11(10), 1345-1355. https://doi.org/10.1002/aur.2005

Torrance, E.P. (1974). The Torrance tests of creative thinking-TTCT Manual and Scoring Guide: Verbal test A, figural test. Lexington, KY: Ginn.

Wang, L., Xu, X., Wang, Q., Healey, G., Su, L., \& Pang, W. (2017). Are individuals with schizophrenia or schizotypy more creative? Evidence from multiple tests of creative potential. Creativity Research Journal, 29(2), 145-156. https://doi.org/10.1080/ 10400419.2017.1302777

Webb, M.E., Little, D.R., Cropper, S.J., \& Roze, K. (2017). The contributions of convergent thinking, divergent thinking, and schizotypy to solving insight and non-insight problems. Thinking \& Reasoning, 23(3), 235-258. https://doi.org/10.1080/ 13546783.2017.1295105

Zabelina, D.L., \& Ganis, G. (2018). Creativity and cognitive control: Behavioral and ERP evidence that divergent thinking, but not real-life creative achievement, relates to better cognitive control. Neuropsychologia, https://doi.org/10.1016/j.neuropsychologia. 2018.02.014

Zabelina, D.L., \& Robinson, M.D. (2010). Creativity as flexible cognitive control. Psychology of Aesthetics, Creativity, and the Arts, 4 (3), 136-143. https://doi.org/10.1037/a0017379

Zhang, W., Sjoerds, Z., \& Hommel, B. (2020). Metacontrol of human creativity: The neurocognitive mechanisms of convergent and divergent thinking. NeuroImage, 210, 116572.

Julie Ramain, Christine Mohr, Ahmad Abu-Akel, University of Lausanne

*Correspondence concerning this article should be addressed to Ahmad Abu-Akel, Institut de Psychologie, Université de Lausanne, Quartier UNIL-Mouline, Géopolis, Lausanne 1015, Switzerland. E-mail: ahmad.abuakel@unil.ch

No funding was associated with this work.

\section{AUTHOR NOTE}

\section{SUPPORTING INFORMATION}

Additional Supporting Information may be found in the online version of this article at the publisher's web-site:

Table S1Descriptive statistics of the Autism Quotient (AQ) and subscales.

Table S2Pearson correlations between the Autism Quotient (AQ) subscales.

Table S3Descriptive statistics of the Community Assessment of Psychic Experiences (CAPE-42) and subscales.

Table S4Pearson correlations between the CAPE-42 subscales.

Table S5Fluency: Mean and standard deviation (SD) of total number of responses.

Table S6Originality: Mean and standard deviation (SD) of total number of unique responses.

Table S7Proportion of unique responses: Mean and standard deviation (SD) of the proportion of unique to total number of responses

Table S8Summary of the regression model examining the effect of cognitive control, attention switching and positive schizotypal traits on context adaptation

Table S9Summary of the moderating effects of attention switching and positive schizotypal traits on the effect of the Proactive Behavioural Index (PBI) on context adaptation. 